\title{
The effect of vegetables and beet fibre on the absorption of zinc in humans from composite meals
}

\author{
BY BRITTMARIE SANDSTRÖ̈ ${ }^{1}$, LENA DAVIDSSON ${ }^{1}$, \\ BARBRO KIVISTÖ ${ }^{1}$, CLAES HASSELBLAD ${ }^{1}$ AND ÅKE CEDERBLAD ${ }^{2}$ \\ ${ }^{1}$ Department of Clinical Nutrition and ${ }^{2}$ Radiation Physics Department, University of \\ Göteborg, Sahlgrenska Hospital, Annedalsklinikerna, S-413 45 Gothenburg, Sweden
}

(Received 7 October 1986 - Accepted 3 March 1987)

1. The absorption of zinc in humans from composite meals, was determined by extrinsic labelling of the meals with ${ }^{65} \mathrm{Zn}$ and measurement of the whole-body retention of the radioisotope.

2. Low- $\mathrm{Zn}$ (mean $25 \mu \mathrm{mol}$ ) chicken meals with $150 \mathrm{~g}$ white bread or $225 \mathrm{~g}$ potatoes, carrots, turnips, cabbage or green peas were studied. The effect of a beet-pulp-fibre preparation used as a breakfast cereal, in bread and as a meat extender on $\mathrm{Zn}$ absorption was also studied.

3. The mean percentage absorption from the chicken meals with white bread, carrots and cabbage was significantly different from the meals with potatoes, turnips and green peas. When the amount of $\mathrm{Zn}$ in the meals was taken into account a slightly higher absorption was observed from the white-bread meal compared with the meals with potatoes and cabbage, while no differences were seen between the vegetable meals.

4. The beet-pulp-fibre preparation did not affect the extent of $\mathrm{Zn}$ absorption when used as a meat extender. The absorption of $\mathrm{Zn}$ was higher when the beet fibre was included in bread than when used as müesli.

5. The results obtained suggest that, besides the low- $\mathrm{Zn}$ content in vegetables, a large intake of vegetables or a pure-vegetable-fibre preparation has no significant effect on $\mathrm{Zn}$ availability from animal-protein-based meals.

The adequacy of zinc in vegetarian diets has been questioned (Harland \& Peterson, 1978; Freeland-Graves et al. 1980) and negative balances of $\mathrm{Zn}$ have been reported when diets high in fibre from fruits and vegetables were consumed (Kelsay et al. 1979; Kelsay \& Prather, 1983). Many plant products contain phytate, which is a potent inhibitor of $\mathrm{Zn}$ absorption (Sandström et al. 1980; Turnlund et al. 1984; Nävert et al. 1985). The fibre components of vegetables, especially those rich in uronic acids, show a strong cationexchange and mineral-binding capacity in vitro (McConnel et al. 1974; Davies, 1978). However, in vitro characteristics of single food components are probably of limited value for predicting $\mathrm{Zn}$ availability in vivo (Davies, 1978).

For evaluation of the absorption and utilization of a mineral for humans, growth rate or tissue retention can hardly be used as in animal experimental models. The conventional metabolic-balance technique has serious methodological limitations for mineral absorption studies. A special problem for $\mathrm{Zn}$ is the large endogenous losses, often of the same magnitude as the amount absorbed, which makes the possibilities of revealing effects on absorption limited. Studies with isotopes of the element of interest are usually more accurate and sensitive and better suited to identify factors that affect absorption. If extrinsic labelling with tracer doses of a radionuclide is used, it is assumed that isotope exchange takes place between the stable $\mathrm{Zn}$ in the meal and the added tracer. The lack of two suitable radionuclides of $\mathrm{Zn}$ to be used simultaneously in absorption studies makes validation in humans of the extrinsic-labelling technique difficult. Flanagan et al. (1985) compared the absorption of Zn from turkey meat labelled extrinsically and intrinsically, and found no difference in absorption. The virtually identical distribution of $\mathrm{Zn}$ and added ${ }^{65} \mathrm{Zn}$ in human milk and infant formulas also suggest rapid and complete exchange of an extrinsic label to food (Sandström et al. 1983). Using stable $\mathrm{Zn}$ isotopes, Janghorbani et al. (1982) found a consistently lower absorption from an extrinsic label than from an intrinsically labelled chicken. However, to 
achieve sufficient enrichment with a stable isotope, tracer doses cannot be used and extrinsic labelling of a composite meal would in that case increase the total $\mathrm{Zn}$ content of the meal. The validity of the extrinsic label used in trace amounts thus still remains to be proved in man for foods other than chicken and turkey, especially as intrinsic labelling with sufficient enrichment is hardly feasible for more than a limited number of food components and the analyses are expensive.

In the present study composite meals were extrinsically labelled with ${ }^{65} \mathrm{Zn}$ and the absorption was determined from the whole-body retention of the isotope. The effect of vegetable fibres on $\mathrm{Zn}$ absorption was studied by comparing meals with different vegetables added to a low- $\mathrm{Zn}$ chicken meal and meals where the fibre content was increased by a beetpulp-fibre preparation. The results indicate that vegetable fibre has no effect on $\mathrm{Zn}$ absorption.

\section{MATERIAL AND METHODS}

\section{Subjects}

Fifty-three men and non-pregnant women, aged 20-34 years and without known disease, volunteered for the study. Their serum $\mathrm{Zn}$ values were $11.4-16 \cdot 1 \mu \mathrm{mol} / 1$ and fell within reference values for our laboratory. The subjects were given written and verbal information about the aim and procedure of the study. Thirty-nine of the subjects participated on two occasions.

The project was approved by the Research Ethical Committee and the Isotopic Committee at Sahlgrenska Hospital.

\section{Test meals}

The effect of vegetable fibre on $\mathrm{Zn}$ absorption was studied in three types of meal: (1) a low$\mathrm{Zn}$ meal of lunch- or dinner-type based on chicken served with bread alone (meal 1) or chicken served with bread and potatoes, carrots, turnips, cabbage or green peas (meals 2-6), (2) breakfast-type meal in which a beet-pulp fibre preparation was added as müesli (meal 7) or incorporated in bread (meal 8), (3) a lunch- or dinner-type meal based on beef and rice (meal 9) was compared with a similar meal in which the beet-pulp fibre preparation was used as a meat extender as recommended by the manufacturer (meal 10). The amounts of raw ingredients in the meals are given in Table 1. The beet fibre was a commercially available fibre preparation made from beet pulp (Fibrex $620^{\mathrm{R}}$; Fibrex AB, a subsidiary to the Swedish Sugar Company, Arlöv). The amount of beet fibre used in meals 7 and 8 was chosen to give a fibre content corresponding to $16 \mathrm{~g}$ wheat bran. To ensure uniformity the chicken meat was minced and meat patties were prepared and a meat sauce was prepared from the beef. The vegetables were minced after cooking in distilled water.

\section{Analyses}

After freeze-drying the test meals were analysed in duplicate for their contents of nitrogen, $\mathrm{Zn}$, iron, calcium and phosphorus. All glassware was washed in $2.5 \mathrm{M}$-hydrochloric acid and rinsed in deionized water before use. $\mathrm{Zn}$ and Fe were assayed by atomic absorption spectrophotometry (Perkin Elmer Model 360, Norwalk, CT 06856, USA), after dryashing in Pyrex beakers overnight $\left(450^{\circ}\right)$. Three drops of nitric acid ( $\left.10 \mathrm{M}\right)$ were added and the ashing continued until a white residue was obtained. The ash was dissolved in $5 \mathrm{ml}$ $5 \mathrm{M}-\mathrm{HCl}$ and the beakers covered with Parafilm (American Can Company, Greenwich, CT 06830 , USA) and left overnight. The contents were then transferred quantitatively to $100-\mathrm{ml}$ flasks, diluted to volume and left for at least $4 \mathrm{~h}$ before analysis. $\mathrm{Ca}$ and magnesium were assayed by atomic absorption spectrophotometry after wet-ashing (290-300, 15 min) of $0.1 \mathrm{~g}$ freeze-dried samples in $1 \mathrm{ml}$ concentrated sulphuric acid with the addition of $3 \mathrm{ml}$ hydrogen peroxide $\left(300 \mathrm{ml} / 1,10 \mathrm{M}\right.$ ). If necessary, another $2 \mathrm{ml} \mathrm{H}_{2} \mathrm{O}_{2}$ were added and 
Table 1. Composition of test meals $(\mathrm{g})$

\begin{tabular}{lccccccccc}
\hline \hline Meal no. & Chicken & White bread & Vegetables & Beet fibre* & Milk & Water & Butter & Beef & Rice $\dagger$ \\
\hline 1 & 75 & 150 & - & - & - & 150 & 25 & - & - \\
$2-6 \ddagger$ & 75 & 50 & 225 & - & - & 150 & 25 & - & - \\
$7-8 \S$ & - & 40 & - & $9 \cdot 2$ & 200 & - & 10 & - & - \\
9 & - & - & - & - & - & 200 & - & 85 & 40 \\
10 & - & - & - & $14 \cdot 0$ & - & 200 & - & 75 & 40 \\
\hline \hline
\end{tabular}

* Fibrex $620^{R}$; Fibrex AB, a subsidiary to the Swedish Sugar Co., Arlöv.

$\dagger$ Dry weight.

$\$ 225$ g potato, carrot, turnip, cabbage or green peas.

$\S$ Beet-pulp fibre added as müesli (meal 7) or incorporated into bread (meal 8).

the tube heated again until the digest was clear and colourless. Deionized water was added to volume and the samples analysed after addition of $1 \mathrm{ml} 0.2 \mathrm{M}$-lanthanum oxide to $10 \mathrm{ml}$ digest. The same digest was used to assay $P$ according to Fiske \& Subbarow (1925). Reference standards for $\mathrm{Zn}, \mathrm{Fe}, \mathrm{Ca}$ and $\mathrm{Mg}$ were prepared from Titrisol ${ }^{\mathrm{R}}$ (Merck, Darmstadt, West Germany). Reference standard materials for $\mathrm{Zn}$ and $\mathrm{Fe}$, with concentrations representative of those found in the diet samples, were run simultaneously and fell within the certified range (Orchard Leaves SRM 1571 and Bovine Liver SRM 1577 (a); National Bureau of Standards, USA). A freeze-dried reference diet from our laboratory was used for control of $\mathrm{Ca}$ and $\mathrm{P}$ analyses. The coefficients of variation for control materials of $\mathrm{Zn}, \mathrm{Fe}$, $\mathrm{Ca}, \mathrm{Mg}$ and $\mathrm{P}$ were $3 \cdot 1,4.4,4 \cdot 1,3.7$ and $5.4 \%$ respectively. $\mathrm{N}$ analysis was performed by a micro-Kjeldahl technique (Technicon AutoAnalyzer, Tecator, Höganäs, Sweden). Starch and dietary fibre components of the diets were assayed according to the method of Theander \& Westerlund (1986). Freeze-dried samples were extracted with ethanol and hexane. Insoluble and soluble fibre of the residue were isolated together by centrifugation after enzymatic removal of starch (with a thermostable $\alpha$-amylase, Type III from Bacillus subtilis; Sigma, St Louis, MO 63178, USA, and amyloglucosidase, Aspergillus niger (EC 3.2.1.3.); Boeringer Mannheim GmbH Biochemica, Mannheim, West Germany) and precipitation of soluble fibre in ethanol $(800 \mathrm{ml} / \mathrm{l})$. Neutral polysaccharides in the dietary fibre fraction were analysed as alditol acetates by gas-liquid chromatography, and uronic acid constituents by a decarboxylation method (Theander \& Áman, 1979). Phytate was assayed by a method suggested by Davies \& Reid (1979). Cation-binding capacity was determined according to Crooke (1969). Freeze-dried food samples were acid-washed with $0.01 \mathrm{M}-\mathrm{HCl}$ followed by titration to $\mathrm{pH} 7.0 \mathrm{using} 0.01$ M-potassium hydroxide. The cation-binding capacity was expressed as $\mathrm{mmol} \mathrm{KOH}$ used per total dry weight.

\section{Zn absorption measurement}

The test meals were labelled with $0.02 \mathrm{MBq}^{65} \mathrm{Zn} \mathrm{Cl}_{2}$ (Amersham International plc, Amersham, Bucks) by addition to the meat patties and minced vegetables, the meat sauce or to the bread dough during preparation of the meals. The activity of each individual meal was measured in the whole-body counter. Owing to the size of the test meals different protocols were used; meals 7 and 8 were served to the subjects after $12 \mathrm{~h}$ of fasting while the other eight test meals, which had a larger volume and a higher energy content, were served at 12.00 hours and preceded at 08.00 hours by a standardized small breakfast consisting of white bread and milk. No other food was allowed for at least $3 \mathrm{~h}$ after intake of the labelled meal. The retention of the radionuclide was measured $14 \mathrm{~d}$ after intake of the labelled meal, 
when it can be assumed that the unabsorbed fraction has left the body. Allowance was made for endogenous excretion of ${ }^{65} \mathrm{Zn}$ in the period between intake and retention measurement, based on the mean retention function obtained after intravenous administration in another group of subjects (Arvidsson et al. 1978), to obtain the absorption value. This excretion in $14 \mathrm{~d}$ is approximately $14 \%$ of the retention value. When the subjects participated a second time, allowance was also made for residual activity from the first meal using the same mean retention function (Arvidsson et al. 1978) to estimate the rate of excretion of retained ${ }^{65} \mathrm{Zn}$. The whole-body counter used consisted of four large plastic scintillators in a floor-roof configuration connected to a multi-channel analyser system (Nuclear data 660, Schaumburg, Illinois, USA). The total effective counting time was $100 \mathrm{~s}$.

\section{In vitro digestion}

The isotope exchange between stable $\mathrm{Zn}$ and added ${ }^{65} \mathrm{Zn}$ was studied after in vitro digestion as described by Hallberg \& Björn-Rasmussen (1981). A weighed amount, $3 \%$ of the total dry weight, of freeze-dried vegetables or chicken was transferred to an Erlenmeyer flask. To this was added $75 \mathrm{ml}$ 'gastric juice' $(0.16 \mathrm{~g}$ pepsin (porcine stomach mucosa, no. P-7012; Sigma), $2 \mathrm{~g}$ sodium chloride, $10 \mathrm{ml} 8 \mathrm{M}-\mathrm{HCl}$ diluted to $500 \mathrm{ml}$ ) and $0.01 \mathrm{MBq}{ }^{65} \mathrm{Zn}$. The flasks were shaken in a water-bath, $37^{\circ}$ for $2 \mathrm{~h}$. The $\mathrm{pH}$ was adjusted to 8 by adding drops of ammonium hydroxide (13 $\mathrm{M})$. Trypsin $(30 \mathrm{mg})$ (bovine pancreas, no. T-8253; Sigma) was added and the flasks incubated at $37^{\circ}$ for another $4 \mathrm{~h}$. The $\mathrm{pH}$ was reduced to 4 with $\mathrm{HCl}$, the samples centrifuged for $15 \mathrm{~min}(2041 \mathrm{~g})$ and the concentrations of $\mathrm{Zn}$ and ${ }^{65} \mathrm{Zn}$ determined in the supernatant fraction.

\section{Statistics}

For statistical evaluation of absorption data, analysis of variance and Duncan's new multiple-range test was used for the chicken meals, and Student's $t$ test for paired observations for the beet-fibre meals. The statistical analysis was performed by a computer package (Mulreg 800; Idatron, Linköping, Sweden)

\section{RESULTS}

\section{Nutrient content of meals}

The contents of $\mathrm{N}, \mathrm{Zn}, \mathrm{Ca}, \mathrm{Mg}, \mathrm{P}$, phytic acid, neutral polysaccharides adjusted for starch content and uronic acid in the meals and the cation-binding capacity of the vegetables and the fibre preparation are given in Table 2 . The chicken meals and the meals with meat sauce had an $\mathrm{N}$ content corresponding to $20-30 \mathrm{~g}$ protein (14-23\% of the energy content of the meals). The $\mathrm{Zn}$ content of the six chicken meals (nos. 1-6) was 15-27 $\mu \mathrm{mol}$, with the chicken meat accounting for $6 \mu \mathrm{mol}$. The beet fibre had a low content of $\mathrm{Zn}(0.3 \mu \mathrm{mol} / \mathrm{g})$ which made a minor contribution to the $\mathrm{Zn}$ content of meals 7 and 8 and resulted in a lower $\mathrm{Zn}$ content when the fibre was used as a meat extender (meal $10 v$ meal 9). The Fe content of the beet fibre was 2-8 $\mu \mathrm{mol} / \mathrm{g}$ and provided about half the Fe content of meal 7 and $30 \%$ of the Fe content of the meal with beef and beet fibre (meal 10). The phytic acid content of the meals was relatively low with the highest amount $(220-230 \mu \mathrm{mol})$ in the meal containing green peas and the meal with $14 \mathrm{~g}$ beet fibre (meals 6 and 10 respectively). The content of neutral polysaccharides varied from 4 to $15 \mathrm{~g}$ and the uronic acids from 0 to $3.5 \mathrm{~g}$, in bread and carrots respectively. The green peas showed the largest cation-exchange capacity. The phytic acid and neutral polysaccharide contents were correlated $(r 0 \cdot 80)$. No correlation was seen between the cation-binding capacity and the neutral polysaccharide contents or the uronic acid contents. 
Vegetable fibre and zinc absorption

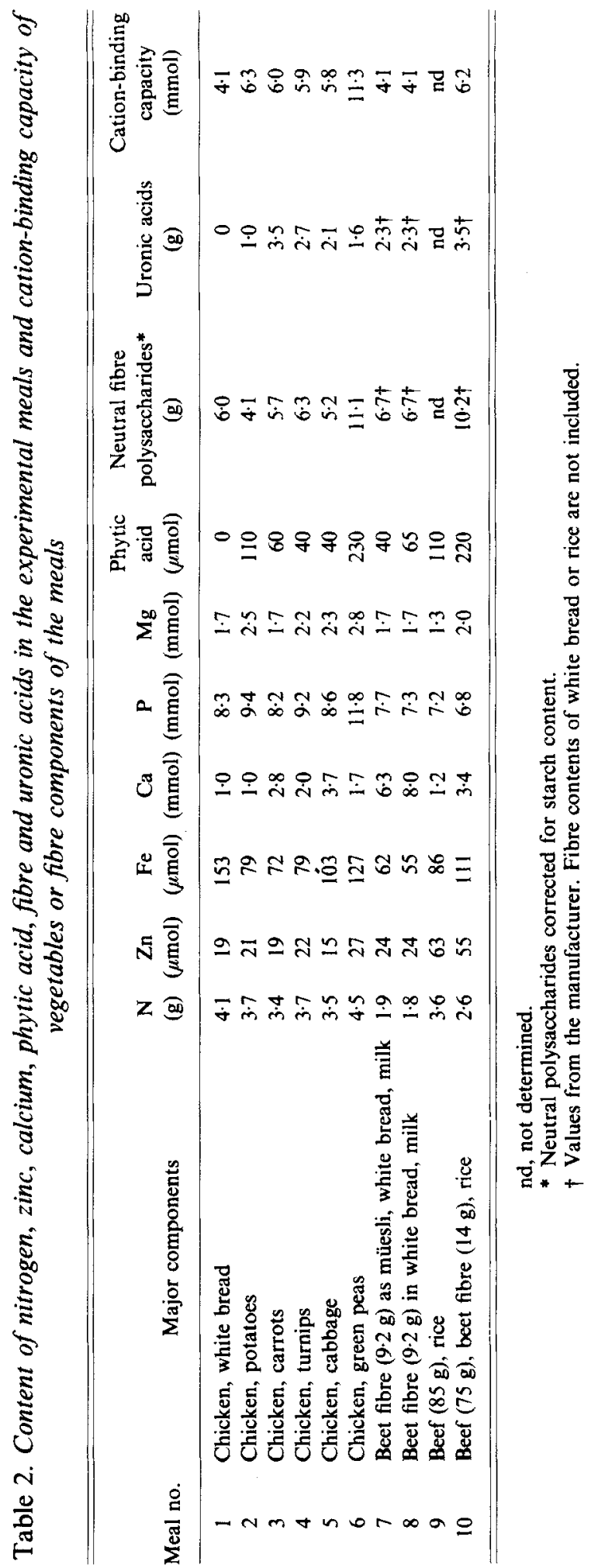


Table 3. Zinc absorption from meals containing different vegetables and beet fibre

(The meals were extrinsically labelled with ${ }^{65} \mathrm{Zn}$ and absorption was determined from measurement of the whole-body retention of the radionuclide)

\begin{tabular}{|c|c|c|c|c|c|c|}
\hline \multirow[b]{3}{*}{ Meal no. } & \multirow[b]{3}{*}{ Major components } & \multirow{3}{*}{$\begin{array}{c}\text { No. of } \\
\text { subjects }\end{array}$} & \multicolumn{4}{|c|}{$\mathrm{Zn}$ absorption } \\
\hline & & & \multicolumn{2}{|c|}{$(\%)$} & \multicolumn{2}{|c|}{$\mu \mathrm{mol}$} \\
\hline & & & Mean & $\mathrm{SD}$ & Mean & SD \\
\hline 1 & Chicken, white bread & 10 & $46 \cdot 1^{\mathrm{a}}$ & $13 \cdot 5$ & $8 \cdot 7^{a}$ & 2.6 \\
\hline 2 & Chicken, potatoes & 13 & $27 \cdot 7^{b}$ & $6 \cdot 2$ & $5 \cdot 7^{b}$ & $1 \cdot 2$ \\
\hline 3 & Chicken, carrots & 13 & $41 \cdot 2^{a}$ & $8 \cdot 8$ & $7 \cdot 8^{\mathrm{a}, \mathrm{b}}$ & $1 \cdot 7$ \\
\hline 4 & Chicken, turnips & 10 & $30 \cdot 2^{\mathrm{b}}$ & 6.9 & $6 \cdot 6^{\mathrm{a}, \mathrm{b}}$ & 1.5 \\
\hline 5 & Chicken, cabbage & 8 & $40 \cdot 9^{\mathrm{a}}$ & $10 \cdot 0$ & $6 \cdot 1^{b}$ & 1.5 \\
\hline 6 & Chicken, green peas & 6 & $27 \cdot 2^{b}$ & $5 \cdot 2$ & $7 \cdot 4^{a, b}$ & 1.4 \\
\hline 7 & Beet fibre $(9 \cdot 2 \mathrm{~g})$ as müesli, white bread, milk & 8 & $27 \cdot 8$ & $12 \cdot 0$ & $6 \cdot 6$ & $2 \cdot 9$ \\
\hline 8 & Beet fibre $(9.2 \mathrm{~g})$ in white bread, milk & 8 & $39 \cdot 5^{*}$ & $11 \cdot 5$ & $9 \cdot 4^{*}$ & $2 \cdot 7$ \\
\hline 9 & Beef $(85 \mathrm{~g})$, rice & 8 & $21 \cdot 8$ & $5 \cdot 1$ & $13 \cdot 7$ & 3.2 \\
\hline 10 & Beef ( $75 \mathrm{~g})$, beet fibre ( $14 \mathrm{~g})$, rice & 8 & $25 \cdot 7$ & $7 \cdot 5$ & $14 \cdot 1$ & $4 \cdot 1$ \\
\hline
\end{tabular}

a, b Values for meals $1-6$ with different superscript letters within each column were significantly different $(P<0.05)$.

* Mean values were significantly different from those for meal $7(P<0.05)$.

\section{Zn absorption}

The absorption of $\mathrm{Zn}$ is given in Table 3. From the chicken meals (nos. 1-6) the highest percentage absorption, $40-46 \%$, was attained from the meals with white bread alone and with carrots or cabbage (nos. 1, 3 and 5). The fractional $\mathrm{Zn}$ absorption from these meals was significantly different $(P<0.05)$ from the other chicken meals. However, when the $\mathrm{Zn}$ content of the meals was taken into account the differences in amount of $\mathrm{Zn}$ absorbed were small. When the beet-fibre preparation was used to replace cereal fibre (meals 7 and 8 ) a higher absorption $(P<0.05)$ was observed when it was included in bread compared with its use as müseli. A partial replacement of meat with beet fibre had no effect on $\mathrm{Zn}$ absorption (meals 9 and 10 ).

The percentage absorption of $\mathrm{Zn}$ from the chicken meals correlated weakly and negatively to the content of phytic acid in the meal and to the in vitro cation-binding capacity $(r-0.73$ and -0.67 respectively) but not to the content of uronic acids. No correlation was found between the absolute amount of $\mathrm{Zn}$ absorbed and any of the analysed components or in vitro characteristics.

\section{In vitro digestion}

After in vitro digestion all ${ }^{65} \mathrm{Zn}$ and virtually all native $\mathrm{Zn}$ was found to be soluble in the supernatant fraction after centrifugation of the acidified slurry of food and 'gastric juice' (Table 4). Only from the white bread was less of the native $\mathrm{Zn}$ than of the added ${ }^{65} \mathrm{Zn}$ recovered in the supernatant fraction after digestion.

\section{DISCUSSION}

In the present study the absorption of $\mathrm{Zn}$ from a composite meal was determined from measurement of the retained activity of a tracer-dose of ${ }^{65} \mathrm{Zn} 14 \mathrm{~d}$ post-absorption by the use of the mean rate of $\mathrm{Zn}$ excretion obtained earlier in another group of subjects (Arvidsson et al. 1978). The rate of $\mathrm{Zn}$ turnover in healthy subjects was, in that study (Arvidsson et 
Table 4. Effect of in vitro digestion on added ${ }^{65} \mathrm{Zn}$ and release of $\mathrm{Zn}$ from food to an aqueous solution

(Food samples were digested with pepsin for $2 \mathrm{~h}$ and trypsin for $4 \mathrm{~h}$ at $37^{\circ}$. The samples were acidified and centrifuged and $\mathrm{Zn}$ and ${ }^{65} \mathrm{Zn}$ measured in the supernatant fraction. The values are means and ranges of four determinations expressed as percentage of total $\mathrm{Zn}$ content and added activity)

\begin{tabular}{lcccc}
\hline & \multicolumn{2}{c}{$\begin{array}{c}\text { Zn in supernatant fraction } \\
(\%)\end{array}$} & & $\begin{array}{c}{ }^{65} \mathrm{Zn} \text { in supernatant fraction } \\
(\%)\end{array}$ \\
\cline { 2 - 5 } Food component & Mean & Range & & Mean \\
\hline White bread & 75 & $65-81$ & 102 & Range \\
Potatoes & 96 & $94-100$ & $99-105$ \\
Carrots & 92 & $89-98$ & 101 & $100-103$ \\
Turnips & 91 & $78-100$ & 100 & $98-102$ \\
Cabbage & 95 & $87-106$ & 96 & $94-98$ \\
Green peas & 93 & $86-100$ & 97 & $95-98$ \\
Chicken & 92 & $88-100$ & 101 & $101-104$ \\
\hline
\end{tabular}

al. 1978), found to be relatively slow and the inter-individual differences were small, which indicates that $\mathrm{Zn}$ intake before or after administration of a labelled diet has little influence on the size of the fraction of the initially absorbed $\mathrm{Zn}$ that is re-excreted during the first $14 \mathrm{~d}$ in subjects with a 'normal' $\mathrm{Zn}$ status, as judged from dietary habits and serum $\mathrm{Zn}$ levels. As most of the subjects participated on two occasions it was also possible to make paired comparisons of the values for the chicken meals. However, this did not in any way change the conclusions and the same is the case if the results for the beet-fibre meals are treated as group values in the statistical analysis. The benefit of determination of each individual's turnover rate by extended measurements over a long period of time is therefore doubtful, especially as this does not improve the precision of the prediction of the early excretion rate before the non-absorbed fraction of the meal has left the body. The effect of a preceding meal on $\mathrm{Zn}$ absorption is not known; by serving a standardized breakfast to the subjects taking meals 1-6 and 9-10 it was hoped to be minimized.

Another potential source of error is the endogenous secretion of $\mathrm{Zn}$ in the intestine before absorption. Isotope exchange that takes place between the label of the meal and the $\mathrm{Zn}$ secreted in the gut would probably give an underestimate of the extent of absorption from the low-Zn meals in the present study. The values obtained are, however, similar to the absorption found from low-Zn diets by Wada et al. (1985) by the use of stable $\mathrm{Zn}$ isotopes. It is also reasonable to assume that the endogenous $\mathrm{Zn}$ secretion is similar after the meals, so that comparisons between the meals can be made.

The results from the in vitro digestion gives, due to the more or less complete recovery of native $\mathrm{Zn}$ in the acidified digest, no validation of the extrinsic-labelling technique. On the other hand the observation that $\mathrm{Zn}$ was in solution at low $\mathrm{pH}$ may suggest that isotope exchange may occur in the stomach, if this has not already taken place during the preparation of the meal. An incomplete isotope exchange would give an overestimate of the absorption since the in vivo percentage absorption increases when the content of $\mathrm{Zn}$ in meals decreases (Sandström et al. 1980; Sandström \& Cederblad, 1980). If the in vitro digestion results are indicative of the isotope exchange in vivo, the lower in vitro extraction of $\mathrm{Zn}$ from the white bread would mean a falsely high absorption. However, for practical and radiation safety reasons it was not suitable to label the food samples for the in vitro study in the same way as the test meals, as this would have required a much higher amount of ${ }^{65} \mathrm{Zn}$ to achieve sufficient activity in the fraction of the meal used. The addition of the 
radionuclide to the dough, as was done for the test bread, might give better conditions for isotope exchange than in the set up of the in vitro study.

Neither the result from the in vitro digestion or the cation-binding capacity could be used to predict the extent of $\mathrm{Zn}$ absorption from the meals. The in vitro digestion demonstrated a high solubility of $\mathrm{Zn}$ after acidification, a procedure that was found necessary in order to be able to centrifuge the otherwise highly-viscous samples. At a $\mathrm{pH}$ similar to that at the site of intestinal absorption, a cation-exchange capacity of the same magnitude as commercial cation exchangers was observed. Similar observations of the high pH-dependency for the solubility of $\mathrm{Zn}$ in food has been observed by Lyon (1984). Further development of in vitro techniques, which better mirror the chemical environment at the site of absorption, is necessary before such methods can be used to estimate the availability of $\mathrm{Zn}$.

Some of the factors determining the extent of $\mathrm{Zn}$ absorption have been identified. We have recently shown a low absorption of $\mathrm{Zn}$ from wholemeal bread or bran rich in phytic acid and that the extent of $\mathrm{Zn}$ absorption is influenced by the $\mathrm{Zn}$ and the protein content of the meal (Sandström et al. 1980; Sandström \& Cederblad, 1980; Nävert et al. 1985). Phytic acid has a high binding constant for $\mathrm{Zn}$ and a ratio of $15: 1$ for phytate: $\mathrm{Zn}$ has been found to impair growth rates in rats (Davies \& Olpin, 1979). The amount of phytic acid in the meals in the present study is low compared with that found in whole-grain cereals ( $10 \mathrm{~g}$ bran contains about $0.5 \mathrm{mmol}$ phytic acid) and despite the low $\mathrm{Zn}$ content of the meals the molar ratio phytic acid: $\mathrm{Zn}$ was less than 10 for all meals.

Dietary fibre content has also been suggested to affect $\mathrm{Zn}$ absorption. A negative $\mathrm{Zn}$ balance during $20 \mathrm{~d}$ on a high-fibre intake in the form of wholemeal bread or $10 \mathrm{~g}$ cellulose has been reported (Reinhold et al. 1976; Ismail-Beigi et al. 1977). Drews et al. (1979) observed an increased faecal $\mathrm{Zn}$ excretion after supplementing the diet with $14 \cdot 2 \mathrm{~g}$ cellulose or hemicellulose during $4 \mathrm{~d}$. As differences in fibre intake affect intestinal transit time (Cummings, 1982), methodological problems can be expected in short-term balances on high-fibre diets. In $30 \mathrm{~d}$ balances reported by Sandstead et al. (1979), no effect of $26 \mathrm{~g}$ of various types of fibre on $\mathrm{Zn}$ balance was observed. The amount of vegetables used in the present study, providing 5-12 g dietary fibre, can be assumed to represent a high intake for a single meal in an animal-protein-based diet. Chicken was used as the protein source because of its low $\mathrm{Zn}$ content and to increase the possibility of revealing nutritionally significant effects on $\mathrm{Zn}$ absorption. The results obtained indicate that vegetables per se do not impair $\mathrm{Zn}$ absorption from this type of meal. The low $\mathrm{Zn}$ content of most fibre-rich vegetables in comparison with cereal fibre sources should, however, be noted.

$\mathrm{Zn}$ absorption from the meals in which the beet-fibre preparation was used as müesli or included in bread, was higher than that observed in earlier studies using bran as the fibre source (Nävert et al. 1985). From meals with similar compositions and using identical test procedures, an absorption of $\mathrm{Zn}$ of $12 \%$ was reported for a bread containing $10 \mathrm{~g}$ bran as compared with $39.5 \%$ in the present study. The difference can probably be attributed to the low phytic acid content of the beet-fibre preparation. However, even after long-term fermentation of the bran-containing bread which reduced the phytic acid content to a level similar to that of the meals in the present study, the absorption of $\mathrm{Zn}$ was lower $(19.8 \%)$ than that from the beet-fibre bread in the present study. It is therefore possible that factors other than phytic acid in fibre-rich cereals could influence $\mathrm{Zn}$ absorption. The difference between meals 7 and 8 in the present study could be due to physico-chemical changes of the fibre during the baking process. We have recently observed that extrusion cooking of a bran product reduces the apparent absorption of $\mathrm{Zn}$ (Kivistö et al. 1986). A milder heat treatment may have other effects on $\mathrm{Zn}$ availability.

The results from meals 9 and 10 also indicate that vegetable fibre is inert as regards $\mathrm{Zn}$ absorption. A vegetable-fibre preparation could therefore be used to partly replace meat 
protein as a way to increase fibre intake when an increased vegetable intake is not possible. The beet-fibre preparation used in the present study had a relatively high mineral content; however it is possible that other ways of processing could result in a lower mineral content and also other effects on mineral absorption. Studies in pigs have shown that the extent of methoxylation of pectin greatly influences Zn absorption (Bagheri \& Guéguen, 1985). The results obtained in the present study do not necessarily apply to other fibre preparations.

This work was supported by grant no. 785902 from the Swedish National Agricultural Market Board and a grant from the Swedish Sugar Company.

\section{REFERENCES}

Arvidsson, B., Cederblad, Å., Björn-Rasmussen, E. \& Sandström, B. (1978). International Journal of Nuclear Medicine and Biology 5, 104-109.

Bagheri, S. \& Guéguen, L. (1985). Reproduction, Nutrition et Développement 25, 705-716.

Crooke, W. M. (1969). Plant and Soil 21, 43-49.

Cummings, J. H. (1982). In Dietary Fiber in Health and Disease, pp. 9-22 [G. V. Vahouny and D. Kritchevsky, editors]. New York: Plenum Publishing Corporation.

Davies, N. T. (1978). Journal of Plant Foods 3, 113-121.

Davies, N. T. \& Olpin, S. E. (1979). British Journal of Nutrition 41, 591-603.

Davies, N. T. \& Reid, H. (1979). British Journal of Nutrition 41, 579-589.

Drews, L. M., Kies, C. \& Fox, H. M. (1979). American Journal of Clinical Nutrition 32, 1893-1897.

Fiske, C. H. \& Subbarow, Y. (1925). Journal of Biology and Chemistry 66, 375-400.

Flanagan, P. R., Cluett, J., Chamberlain, M. J. \& Valberg, L. S. (1985). Journal of Nutrition 115, 111-122.

Freeland-Graves, J. H., Ebangit, M. L. \& Hendrikson, P. J. (1980). American Journal of Clinical Nutrition 33, 1757-1766.

Hallberg, L. \& Björn-Rasmussen, E. (1981). American Journal of Clinical Nutrition 34, 2808-2815.

Harland, B. F. \& Peterson, M. (1978). Journal of the American Dietetic Association 72, 259-264.

Ismail-Beigi, F., Reinhold, J. G., Faraji, B. \& Abadi, P. (1977). Journal of Nutrition 107, 510-518.

Janghorbani, M., Isfan, N. W., Pagounes, J. O., Steinke, F. H. \& Young, V. R. (1982). American Journal of Clinical Nutrition 36, 537-545.

Kelsay, J. L., Jacob, R. A. \& Prather, E. S. (1979). American Journal of Clinical Nutrition 32, 2307-2311.

Kelsay, J. L. \& Prather, E. S. (1983). American Journal of Clinical Nutrition 38, 12-19.

Kivistö, B., Andersson, H., Cederblad, C., Sandberg, A.-S. \& Sandström, B. (1986). British Journal of Nutrition $55,255-260$.

Lyon, D. B. (1984). American Journal of Clinical Nutrition 39, 190-195.

McConnel, A. A., Eastwood, M. A. \& Mitchell, W. D. (1974). Journal of the Science of Food and Agriculture 25, $1457-1464$.

Nävert, B., Sandström, B. \& Cederblad, Å, (1985). British Journal of Nutrition 53, 47-53.

Reinhold, J. G., Faradji, B., Abadi, P. \& Ismail-Beigi, F. (1976). Journal of Nutrition 106, 493-503.

Sandstead, H. H., Klevay, L. M., Jacob, R. A., Munoz, J. M., Logan G. M. Jr, Reck, S. J., Dintzis, F. R., Inglett, G. E. \& Shuey, W. C. (1979). In Dietary Fibers: Chemistry and Nutrition, pp. 147-156. [G. E. Inglett and S. I. Falkehag, editors]. New York: Academic Press.

Sandström, B., Arvidsson, B., Cederblad, Å. \& Björn-Rasmussen, E. (1980). American Journal of Clinical Nutrition 33, 739-745.

Sandström, B. \& Cederblad, Å. (1980). American Journal of Clinical Nutrition 33, 1778-1783.

Sandström, B., Keen, C. L. \& Lönnerdal, B. (1983). American Journal of Clinical Nutrition 38, 420-428.

Theander, O. \& Åman, P. (1979). Swedish Journal of Agricultural Research 9, 97-106.

Theander, O. \& Westerlund, E. (1986). Journal of Agriculture and Food Chemistry 34, 330-336.

Turnlund, J. R., King, J. C., Keyes, W. R., Gong, B. \& Michel, M. C. (1984). American Journal of Clinical Nutrition 40, 1071-1077.

Wada, L., Turnlund, J. R. \& King, J. R. (1985). Journal of Nutrition 115, 1345-1354 . 